AperTO - Archivio Istituzionale Open Access dell'Università di Torino

\title{
Hypertension and Acromegaly
}

\section{This is a pre print version of the following article:}

Original Citation:

\section{Availability:}

This version is available http://hdl.handle.net/2318/1719505

since 2022-10-12T09:22:12Z

Published version:

DOI:10.1016/j.ecl.2019.08.008

Terms of use:

Open Access

Anyone can freely access the full text of works made available as "Open Access". Works made available under a Creative Commons license can be used according to the terms and conditions of said license. Use of all other works requires consent of the right holder (author or publisher) if not exempted from copyright protection by the applicable law. 


\section{HYPERTENSION AND ACROMEGALY}

2 Soraya Puglisi ${ }^{1}$, Massimo Terzolo ${ }^{1}$.

$3 \quad{ }^{1}$ Internal Medicine 1, Department of Clinical and Biological Sciences, University of Turin, Italy;

4

5 Soraya Puglisi

6 Internal Medicine 1, Department of Clinical and Biological Sciences, San Luigi Gonzaga Hospital,

7 Regione Gonzole 10, 10043 Orbassano, Italy; tel: +39 011 9026292, fax: +39 0116705456

8 e-mail: sorayapuglisi@yahoo.it

9

10 Corresponding Author: Massimo Terzolo

11 Internal Medicine 1, Department of Clinical and Biological Sciences, San Luigi Gonzaga Hospital,

12 Regione Gonzole 10, 10043 Orbassano, Italy; tel: +39 011 9026292, fax: +39 0116705456

13 e-mail: terzolo@usa.net

14

15

Declaration of interest

17 Soraya Puglisi has stated explicitly that there are no conflicts of interest in connection with this 18 article.

19 Massimo Terzolo has received research grants from Novartis.

22 KEY WORDS: blood pressure, cardiovascular risk, anti-hypertensive treatment, cardiovascular 23 complication, mortality, prevalence, pathogenesis, sleep apnea. 
KEY POINTS:

- Hypertension is one of the most important and common complications in acromegaly, responsible to increased cardiovascular risk, higher rate of hospitalization and greater costs for the disease management.

- The pathogenesis has not yet been fully elucidated and likely includes multiple factors.

- A comprehensive, patient-centered approach, focusing not only on the biochemical control of acromegaly, but also on an early diagnosis of hypertension and a prompt antihypertensive treatment, is required for optimal patient care.

\section{SYNOPSIS}

Hypertension is one of the most frequent complications in acromegaly, with a median frequency of $33.6 \%$ (ranging from 11 to $54.7 \%$ ). Although the pathogenesis has not been fully elucidated, it is probably the result of concomitant factors leading to expansion of extracellular fluid volume, increase of peripheral vascular resistances and development of sleep apnea syndrome. As the effect of normalization of GH and IGF1 excess on blood pressure levels is unclear, an early diagnosis of hypertension and prompt anti-hypertensive treatment are eagerly recommended, regardless of the specific treatment of the acromegalic disease and the level of biochemical control attained. 


\section{INTRODUCTION}

43 Acromegaly is a rare, chronic disease whose clinical manifestations are the consequence of GH and

44 IGF1 excess that is usually caused by a GH-secreting pituitary adenoma ${ }^{\mathbf{1}}$. The disease is associated with a significant number of complications and comorbid conditions, mainly affecting the cardiovascular $(\mathrm{CV})$ system $^{2}$. Arterial hypertension is among the most frequent $\mathrm{CV}$ complications of acromegaly; however, its role as a prognostic factor is not definitely established ${ }^{3-7}$, despite the negative impact of hypertension on the acromegalic cardiomiopathy ${ }^{\mathbf{8}, 9}$. The classic view that CV disease is the main culprit for the excess mortality in acromegalic patients ${ }^{\mathbf{2}, 4}$ has been revisited in more recent studies ${ }^{\mathbf{6 , 1 0 , 1 1}}$. Nevertheless, CV disease is associated with an important disease burden, and significantly increases the rate of hospitalization and the health care costs ${ }^{\mathbf{1 2}}$.

\section{PREVALENCE AND CHARACTERISTICS}

54 The frequency of hypertension in acromegaly varies from $11 \%$ to $54.7 \%$, averaging $33.6 \%$, as

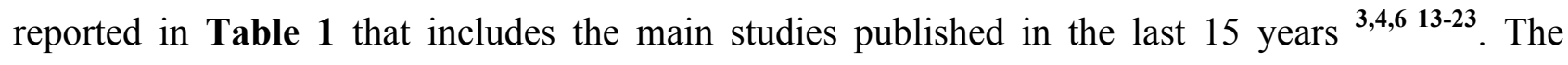
variability found in the prevalence of hypertension could be attributed to the different diagnostic criteria adopted over different periods of recruitment, and to population-related risk factors (genetic and racial differences, prevalence of obesity, unhealthy life style, such as smoking and excessive sodium or alcohol intake). It is worth of note that all these studies were retrospective and reported only on office measurements of blood pressure (BP), likely overestimating the actual frequency of hypertension compared with the ambulatory blood pressure monitoring (ABPM). This caveat was first demonstrated by Minniti et al. ${ }^{24}$, who reported a frequency of $42.5 \%$ of hypertension in acromegalic patients with office BP measurements versus a frequency of $17.5 \%$ with ABPM. Similar findings were recently found by Costenaro et al. ${ }^{25}$, who demonstrated a rate of 23\% hypertension with ABPM versus 32\% with clinical measurements. Interestingly, they reported that BP levels recorded by ABPM were correlated with GH and IGF1 concentrations. 
67 The correlation between severity of hypertension and GH, or IGF1 levels, has been investigated in several studies, but findings are discordant ${ }^{\mathbf{6 , 2 6 , 2 7}}$. A recent paper tried to dissect the problem, showing a positive correlation between BP levels and IGF1 concentrations when the latter were above the upper limit of normalcy, with an inverse relationship when IGF1 levels were within the normal range ${ }^{28}$. The analysis included several studies, most of which have been carried out in nonacromegalic patients, and supports a direct relationship in states characterized by overtly elevated IGF1, like uncontrolled acromegaly. In addition, it is plausible that other variables are important determinants of hypertension in acromegaly, such as the duration of disease ${ }^{27,29}$, patient age and body mass index, while family history of hypertension or gender have a more controversial role ${ }^{\mathbf{1 9}}$, 27,30 .

Hypertension in acromegalic patients is generally regarded as a mild disease that can be easily managed with standard antihypertensive drugs ${ }^{31}$. A peculiar pattern of acromegaly-associated hypertension may be found in higher diastolic BP and lower systolic BP levels compared to nonacromegalic hypertensive subjects ${ }^{27}$, 32. Furthermore, studies using ABPM found a higher prevalence of non-dippers (almost 50\%) in acromegalic hypertensive patients compared with patients with primary hypertension ${ }^{32,33}$. The non-dipping pattern is shared with other types of secondary hypertension and is associated with increased CV morbidity and mortality.

\section{PATHOGENESIS}

The pathogenesis of hypertension in acromegaly has not been yet fully clarified, but a multifactorial origin is the most convincing explanation (Figure 1). The development of hypertension may be attributable to a combined effect of a chronic GH/IGF1 excess on different systems that finally causes expansion of extracellular fluid volume, increase of peripheral vascular resistances, and development of the sleep apnea syndrome. 
94 The increase of total extracellular fluid volume is secondary to sodium and water retention by the kidney, due to direct and indirect effects of GH/IGF1 ${ }^{34}$.

\section{a) Direct GH anti-natriuretic effects}

The hypothesis of a GH direct effect fits well with the demonstration of $\mathrm{GH}$ receptors in human adrenal cortex ${ }^{35}$. In rat models of acromegaly, GH had an aldosterone-independent anti-natriuretic effect, mediated through the epithelial $\mathrm{Na}^{+}$channels $(\mathrm{ENaC})$ of collecting ducts ${ }^{\mathbf{3 6}}$. The rats received furosemide, an antidiuretic drug able to inhibit the sodium reabsorption NCCK2 channels in the loop of Henle, and amiloride, which blocks the $\mathrm{ENaC}$ channels in the collecting ducts. In acromegalic rats, the furosemide-induced natriuresis was lower compared to controls, whereas the amiloride-induced natriuresis was higher, confirming the hypothesis that GH stimulates sodium transport in the distal nephron via ENaC channels. The increased activity of ENaC channels in acromegaly was demonstrated also in humans, using a similar model of pharmacological challenge with amiloride and furosemide ${ }^{37}$.

\section{b) Effects of $G H$ on the renin-angiotensin-aldosterone system}

110 The relationship between the renin-angiotensin-aldosterone system (RAAS) and GH/IGF1 excess

111 has been carefully evaluated in the last decades, but remains controversial. The leading hypothesis

112 is that increased aldosterone levels, directly stimulated by GH excess, contribute to hypertension in 113 acromegaly without stimulation of plasma renin activity (PRA) ${ }^{38}$. As matter of fact, no change has 114 been found in RAAS activity during IGF1 administration ${ }^{39}$ and low levels of PRA have been 115 consistently detected in acromegalic patients ${ }^{\mathbf{4 0}, \mathbf{4 1}}$.

116 A significant direct correlation between $\mathrm{GH}$ and aldosterone values in acromegalic patients has

117 been observed and serum aldosterone concentration significantly decreased after normalization of 118 GH secretion due to surgical cure, whereas renin concentrations remained unaffected. In animal 
models, the association of chronic GH excess with increased aldosterone was independent of renin,

120 IGF-I, or adrenal aldosterone synthase expression ${ }^{38}$. On the contrary, a study concerning the 121 polymorphisms of genes involved in the RAAS has underlined the role of aldosterone synthase 122 (CYP11B2), showing that acromegalic patients with the CYP11B2 - 344CC genotype were affected 123 by hypertension more frequently than patients with the CT/TT genotypes, with a significant 124 increase of systolic BP ${ }^{42}$. Conversely, no significant effect of polymorphisms in other genes, such 125 as angiotensinogen (AGT) or angiotensin-converting enzyme (ACE), was reported in agreement 126 with the findings of a more recent study ${ }^{43}$.

\section{c) IGF1-mediated inhibition of ANP}

129 Some studies showed a reduction of atrial natriuretic peptide (ANP) secretion in acromegalic 130 patients. McKnight and colleagues ${ }^{44}$ compared plasma ANP levels of patients with active 131 acromegaly versus healthy subjects, before and after a 4-h intravenous infusion of normal saline. 132 ANP levels rose significantly in the control group, whereas in acromegalic patients they did not 133 respond to saline stimulation. Although the basal ANP values were similar between the two groups, 134 the 4-h ANP levels were significantly higher in the group of healthy subjects than in the 135 acromegalic group. A few years later, Moller et al. ${ }^{39}$ demonstrated that the inhibition of ANP136 induced natriuresis is mediated by IGF-I.

\section{d) Insulin mediated effect}

139 It is well known that acromegaly is often associated with insulin resistance and hyperinsulinemia.

140 The anti-natriuretic effect of insulin has long been debated, but an action on renal sodium 141 absorption has confirmed ${ }^{45}$. Although experimental studies in acromegalic patients are not 142 available, the pathophysiological role of insulin-mediated changes in sodium balance fits well with 143 the finding of higher insulin levels after oral glucose tolerance load in hypertensive than 144 normotensives acromegalic patients ${ }^{46}$, and higher BP levels in hyperinsulinemic acromegalic 
145 patients ${ }^{47}$. On the other hand, other studies did not find a difference in fasting or post-load plasma 146 insulin values between hypertensive and normotensives acromegalic patients ${ }^{48,49}$, suggesting that

147 other factors could be involved in the pathogenesis, such as the insulin-mediated activation of the 148 sympathetic nervous system ${ }^{\mathbf{5 0}, \mathbf{5 1}}$.

\section{e) Sympathetic nervous system mediated effect}

151 The influence of the sympathetic nervous system on tubular processing of sodium is well known ${ }^{\mathbf{5 1}}$. 152 On the contrary, controversial data on the role of an impaired sympathetic tone in acromegaly have 153 been reported in the last decades ${ }^{\mathbf{5 0}}$. In this area of debate, the assessment of the 24-hour profiles of 154 plasma catecholamine levels and BP in 14 acromegalic patients (before and after pituitary surgery) 155 and 8 healthy controls demonstrated a flattened 24-hour profile of norepinephrine and BP in 156 acromegalic patients, while the circadian norepinephrine rhythm was restored after surgery with normalization/reduction of GH/IGF-I levels ${ }^{\mathbf{5 2}}$.

160 The effect of chronic GH and IGF-I excess on vascular resistances could explain the more apparent 161 increase of diastolic versus systolic BP in acromegalic patients ${ }^{27,32}$. Recently, a study assessed with renal ultrasonography 57 acromegalic patients and showed that the Renal Resistive Index (RRI) was

163 higher in 16 hypertensive acromegalic patients compared to 49 normotensive patients ${ }^{\mathbf{5 3}}$. Moreover, 164 the RRI value was independently related to the presence of hypertension and correlated with IGF-1 165 levels, supporting the hypothesis of a link between the severity of acromegaly and hypertension.

\section{a) Stimulation of vascular RAAS and vascular hypertrophy}

168 It has been demonstrated in vitro that both IGF1 and insulin were able to stimulate angiotensinogen 169 production in cultures of vascular smooth muscle cells ${ }^{54}$. Interestingly, the same study showed the 170 role of the two hormones in the development of vascular hypertrophy, through activation of the 
vascular RAAS. It is conceivable that the same mechanism could play a role in the pathogenesis of hypertension in acromegaly, according to studies that demonstrated an association between

173 hyperinsulinemia and hypertension in this group of patients ${ }^{46,47}$. This hypothesis suits well with 174 evidence of a hypertrophic remodeling of subcutaneous small resistance arteries in acromegalic 175 patients compared with the eutrophic remodeling in patients with essential hypertension ${ }^{\mathbf{5 5}}$. The 176 assessment of the structure of small arteries in biopsies of subcutaneous fat and of the calculated 177 media-to-lumen ratio and growth indices demonstrated the effect of growth factors in the 178 development of vascular morphological alterations. A weak, but statistically significant correlation 179 between the media-to-lumen ratio and IGF-1 values was also found in this small group of 9 180 acromegalic patients. Similar findings on vascular hypertrophy in acromegaly, and a positive 181 association between wall thickness and IGF-I levels, have been showed in a subsequent study 182 including a larger sample of 41 patients ${ }^{\mathbf{5 6}}$.

\section{b) Endothelial dysfunction}

185 The comparison of the cutaneous vasoreactivity responses of 10 normotensive acromegalic patients 186 with 10 healthy controls demonstrated in the former group an impaired endothelium-dependent 187 vasodilatation, which is mediated by nitric oxide (NO) ${ }^{\mathbf{5 7}}$. The NO pathway has been subsequently 188 evaluated, also taking in consideration its effects on vascular resistance, platelet aggregation and 189 inhibition of smooth muscle cell proliferation. A few years later, it was demonstrated a decrease of 190 NO concentrations in acromegalic patients, due to a reduced endothelial NO synthase expression, 191 and an inverse correlation between NO and GH/IGF-1 levels, and duration of acromegaly ${ }^{\mathbf{5 8}}$. 192 Several recent studies confirmed the impairment of flow-mediated vasodilation ${ }^{\mathbf{5 9}, \mathbf{6 0}}$ and the role of 193 reduced NO levels in acromegaly ${ }^{\mathbf{5 6}, \mathbf{6 1}}$, which may contribute to both hypertension and erectile 194 dysfunction in male acromegalic patients ${ }^{62}$. Finally, it deserves to be mentioned also the 195 association between endothelial dysfunction and insulin resistance ${ }^{63}$, as a further possible 196 mechanism in this complex scenario. 
199 The evidence of an over-reactivity to sympathetic stimulation in acromegaly has been provided 200 using a cold pressor test to study sympathetic vasoreactivity ${ }^{57}$. The study showed a significantly 201 more pronounced increase in systolic BP, and a trend to a greater decrease in skin perfusion, in 202 acromegalic patients compared with healthy control, with a greater, although not statistically 203 significant, vasoconstriction in acromegaly. On the other hand, there are few and contradictory data 204 on catecholamine levels without any clear evidence of increased sympathetic tone in acromegalic 205 patients ${ }^{\mathbf{5 0}}$. A study comparing acromegalic patients and hypertensive control reported a 24-hour 206 catecholamine secretion that was quantitatively similar, but without any circadian rhythm and a 207 normal fall during the night in acromegalic patients ${ }^{\mathbf{5 2}}$. This is in agreement with other findings 208 indicating a reduced nocturnal fall in BP in both normotensive and hypertensive acromegalic 209 patients, with a prevalence of the "non-dipper" profile (mean nocturnal BP $\leq 10 \%$ of the average daytime BP) ${ }^{32,64}$.

\section{SLEEP APNEA}

213 Sleep apnea syndrome (SAS) is common in acromegaly, mainly due to anatomical changes in the 214 entire respiratory system ${ }^{29}$. Particularly, alterations of the bone and soft tissues in the craniofacial region (mandibular prognathism due to growth effect of GH/IGF1, macroglossia, pharyngeal and 216 laryngeal swelling due to sodium and water retention) reduce the airflow during sleep, causing 217 repeated hypoxic and hypercapnic episodes ${ }^{65}$. Therefore, the prevalence of SAS in active 218 acromegaly is up to $45-80 \%$ of patients, according to different studies ${ }^{\mathbf{6}}$. As in the general 219 population, SAS is independently associated with hypertension and cardiovascular disease ${ }^{\mathbf{6 7}, \mathbf{6 8}}$, and 220 the role of SAS in the pathogenesis of hypertension in acromegaly should not be overlooked due to 221 its contribution to the flattening of the nocturnal BP fall. 
224 A recent consensus on the diagnosis and treatment of acromegaly complications ${ }^{31}$ recommended an 225 early diagnosis and aggressive treatment of high BP levels, regardless of the specific treatment of 226 acromegaly. Therefore, BP measurement is always recommended at diagnosis of acromegaly, but it 227 must be reassessed during the long-term follow-up (every 6 months, or when acromegaly treatment 228 is changed, if hypertensive) ${ }^{31}$. It could be argued that the sole use of office measurements can lead 229 to an overestimation of the frequency of hypertension ${ }^{24,25}$, but this risk could be minimized using a 230 self-measurement pressure diary or AMBP.

231 The choice of the antihypertensive agents, mainly angiotensin converting enzyme inhibitors 232 [ACEi], angiotensin II receptor blockers [ARBs], thiazide-type diuretics, calcium channel blockers, 233 does not significantly differ from the non-acromegalic patients and there is no recommendation on a 234 preferential class of drugs ${ }^{31}$, although recent researches have suggested that amiloride is a 235 potentially interesting option ${ }^{36,37}$. Moreover, a recent study including a small number of 236 acromegalic patients has demonstrated with cardiac magnetic resonance that cardiac indices were 237 improved in the hypertensive subjects on ACEi or ARBs compared with other antihypertensive 238 drugs ${ }^{69}$. Given that sleep apnea exacerbates hypertension ${ }^{\mathbf{6 8}}$, its effective management is mandatory 239 to improve BP control.

EFFECT OF ACROMEGALY CONTROL

243 The effect of attaining control of GH and IGF1 excess on BP levels was heterogeneous across 244 studies. In 2008, a study showed significantly lower systolic and diastolic BP levels in 76 245 acromegalic patients achieving disease control after 36 months, comparing with the remaining 29 246 uncontrolled patients. Moreover, increased doses, and/or greater number of antihypertensive drugs, 247 were needed in patients with uncontrolled disease ${ }^{70}$. In addition, the biochemical control of 248 acromegaly seems to have beneficial effects on BP levels also in non-hypertensive patients, 
249 preventing the progression towards hypertension ${ }^{33}$. A recent study, including 121 acromegalic 250 patients (of whom 79 achieving biochemical control during follow-up), confirmed that hypertension 251 was more frequent in uncontrolled acromegaly ${ }^{20}$.

252 However, some recently published articles downplayed the role of acromegaly control on BP levels. 253 A study including 552 acromegalic patients, stratified according to disease activity at the last visit, 254 demonstrated that the prevalence of hypertension was not modified by the successful treatment of 255 acromegaly ${ }^{71}$. Previously, a research including 200 acromegalic patients did not demonstrated at 256 multivariate analysis that the lack of biochemical control was a predictor of hypertension, although 257 the univariate analysis showed a six-fold higher risk of hypertension in uncontrolled patients 258 compared with patients in remission after surgery ${ }^{30}$. Although the question is still open, we 259 reviewed a selection of papers addressing this issue that have been classified according to the 260 treatment approach (Table 2).

SURGERY

263 The surgical removal of a GH-secreting adenoma, in most cases using a transsphenoidal approach, 264 still represents the mainstay of treatment and a potentially rapid curative option ${ }^{72}$. Several studies 265 have investigated the impact of neurosurgery on BP levels and reported contrasting findings, 266 probably due to different sample sizes, type of measurements (clinical measurements versus 267 ABPM), BP cut-offs used, and timing of assessment after surgery. Studies showed a significant 268 lowering of both clinical systolic and diastolic BP at $3^{73}$ and 6 months after surgery ${ }^{74}$. The first 269 study used only office BP measurement, whereas ABPM was also performed in the second study 270 showing a significant postoperative decrease of the 24-h diurnal and nocturnal systolic BP profile 271 with no change in the diastolic profile. Moreover, a circadian rhythm of BP was restored in most of 272 the patients with a blunted preoperative BP profile. Similarly, Minniti and colleagues ${ }^{75}$, using both 273 clinical measurement and ABPM before and 6 months after surgery, demonstrated a significant 274 decrease of the clinical and 24-h systolic BP in 15 well-controlled patients after surgery, in contrast 
with no change in 15 poorly controlled acromegalic subjects. In the first group, a normal BP circadian rhythm was restored in almost all patients, whereas no changes occurred in the second 277 group. The reduction in systolic, but not diastolic BP, 6 months after surgery was confirmed by 278 Reyes-Vidal and colleagues ${ }^{\mathbf{7 6}}$; in addition, a lowered diastolic BP was found 1 year after surgery. 279 Colao and colleagues ${ }^{77}$, comparing 56 acromegalic patients controlled with SSA and 33 cured with 280 surgery, reported at 1 year a significant lowering of diastolic (but not systolic) BP in both groups. 281 Interestingly, the effect of a long-term effect of remission on diastolic BP was confirmed by a study 282 reporting that after a mean period from surgery of 12.7 years diastolic (but not systolic) BP was 283 significantly lower in patients in remission than in patients with active acromegaly ${ }^{\mathbf{7 8}}$.

\section{SOMATOSTATIN ANALOGUES}

286 Although surgery is the treatment of choice, SSA (octreotide and lanreotide and the secondgeneration multireceptor-targeted pasireotide) are the first-line medical therapy, with a proved efficacy in more than $50 \%$ of patients, and being able to improve significantly acromegalic comorbidities ${ }^{\mathbf{7 9}, \mathbf{8 0}}$. A retrospective study comparing 36 acromegalics treated with SSA and 33 sex-, age-, and BMI-matched patients cured after surgery, did not find any significant difference in diastolic and systolic BP between the two groups ${ }^{\mathbf{8 1}}$. Previously, a prospective study showed a significant reduction of systolic and diastolic BP in 36 acromegalic patients treated for 12-24months with depot long-acting octreotide ${ }^{\mathbf{8 2}}$. In 2007, however, a metanalysis demonstrated that SSA therapy did not lead to a clear fall in BP, suggesting a pressure-independent effect of SSA on heart ${ }^{83}$. In 2009, a study evaluated the efficacy of 5 years of depot SSA as first-line therapy in acromegaly and demonstrated a reduction in BP and a reduction in the rate of hypertension ${ }^{\mathbf{8 4}}$.

\section{PEGVISOMANT}

The second-line medical therapy consists of Pegvisomant (PEG), an antagonist of the GH receptor 
301 responsible of permanent remission in selected patients with SSA-resistant acromegaly ${ }^{\mathbf{8 9}}$. However, 302 data on its impact on BP levels are limited to small size studies and are conflicting.

303 A prospective study including 16 patients with SSA-resistant acromegaly treated with PEG 304 demonstrated no change in systolic and diastolic BP overall; however, a significant decrease of 305 diastolic BP was apparent in the 4 hypertensive patients evaluated separately ${ }^{\mathbf{9 0}}$. Interestingly, 306 whereas a 6-month therapy with PEG in 17 acromegalic patients did not significantly change systolic and diastolic BP ${ }^{91}$, a 18 -months therapy with PEG in 10 acromegalic patients significantly

309 decreased diastolic BP only in the hypertensive patients ${ }^{92}$. A recent prospective study of the same 310 group, including 50 acromegalic patients assessed at baseline, after long-term treatment with SSA 311 and after 12 and 60 months of combined treatment with SSA and PEG, demonstrated only a slight 312 but non-significant improvement of systolic and diastolic BP after combined treatment compared 313 with long-term SSA therapy ${ }^{93}$. In 2010, Berg and colleagues ${ }^{94}$ assessed BP levels at baseline and 314 after 12 months of PEG therapy in 62 acromegalic patients, of which 42 had normalized IGF-I 315 (controlled patients) and 20 had reduced, but not normalized IGF1 (partially controlled patients). 316 Systolic BP was significantly lower in the former than in the latter group, and decreased 317 significantly during treatment only in controlled patients, but not in partially controlled patients. 318 Diastolic BP was significantly lower in controlled than in partially controlled patients, but without 319 significant changes in each group compared with baseline ${ }^{94}$. More recently, a retrospective study 320 including 96 patients treated with different modalities (surgery, SSA or PEG) reported a significant 321 reduction, among the 11 patients who were hypertensive at diagnosis and whose antihypertensive 322 treatment was not modified, in systolic BP after surgery, but not after PEG treatment, regardless of 323 IGF1 changes ${ }^{95}$.

326 Cabergoline is a dopamine agonist, used in acromegaly as an adjuvant treatment as monotherapy in 
327 patients with mild disease or in combination with SSA ${ }^{\mathbf{7 2}}$. To date, no prospective randomized trial 328 evaluating its efficacy in acromegaly is available and no study reporting its effect on hypertension 329 in acromegalic patients has been carried out.

RADIOTHERAPY

332 Radiotherapy is currently considered as a third-line option, in acromegalic patients uncontrolled 333 after surgery and medical therapy, or in case of aggressive GH-secreting tumors ${ }^{\mathbf{7 2}}$. To our 334 knowledge, no data focusing on the effect of radiotherapy on hypertension in acromegalic patients 335 has been reported.

CONCLUSION

338 Hypertension is one of the most important and common complications in acromegaly. Its 339 pathogenesis has not yet been fully elucidated, and likely includes multiple factors. A 340 comprehensive, patient-centered approach, focusing not only on the biochemical control of 341 acromegaly, but also on an early diagnosis of hypertension and a prompt anti-hypertensive 342 treatment, is required for optimal patient care. However, there is an urgent need of prospective, 343 large-scale studies focusing on hypertension, and its response to treatment of acromegaly, to solve 344 the conundrum whether control of GH-IGF1 excess ameliorates BP levels. 


\section{REFERENCES}

1. Melmed S. Acromegaly. N Engl J Med 1990; 322:966-77.

2. Colao A, Ferone D, Marzullo P, et al. Systemic complications of acromegaly: epidemiology, pathogenesis, and management. Endocr Rev 2004; 25:102-52.

3. Mestron A, Webb SM, Astorga R, et al. Epidemiology, clinical characteristics, outcome, morbidity and mortality in acromegaly based on the Spanish Acromegaly Registry (Registro Espanol de Acromegalia, REA). Eur J Endocrinol. 2004;151:439-46.

4. Holdaway IM, Rajasoorya RC, Gamble GD. Factors influencing mortality in acromegaly. J Clin Endocrinol Metab 2004; 89:667-674.

5. Holdaway IM, Bolland MJ, Gamble GD. A metanalysis of the effect of lowering serum levels of GH and IGF-1 on mortality in acromegaly. Eur. J. Endocrinol. 2008; 159: 89-95.

6. Arosio M, Reimondo G, Malchiodi E, et al. Predictors of morbidity and mortality in acromegaly: an Italian survey. Eur J Endocrinol. 2012; 167:189-98.

7. Ragonese M, Alibrandi A, Di Bella G, et al. Cardiovascular events in acromegaly: distinct role of Agatston and Framingham score in the 5-year prediction. Endocrine. 2014; 47:206-12.

8. López-Velasco R, Escobar-Morreale HF, Vega B, et al. Cardiac involvement in acromegaly: specific myocardiopathy or consequence of systemic hypertension? J Clin Endocrinol Metab. 1997; 82:1047-53.

9. Colao A, Baldelli R, Marzullo P, et al. Systemic hypertension and impaired glucose tolerance are 364 independently correlated to the severity of the acromegalic cardiomyopathy. J Clin Endocrinol 365 Metab 2000; 85:193-199.

366 10. Mercado M, Gonzalez B, Vargas G, et al. Successful mortality reduction and control of 367 comorbidities in patients with acromegaly followed at a highly specialized multidisciplinary clinic. 368 J Clin Endocrinol Metab 2014; 99:4438-4446.

369 11. Ritvonen E, Löyttyniemi E, Jaatinen P, et al. Mortality in acromegaly: a 20-year follow-up 370 study. Endocr Relat Cancer 2015; 23:469-480. 
371 12. Broder MS, Neary MP, Chang E, et al. Treatments, complications, and healthcare utilization associated with acromegaly: a study in two large United States databases. Pituitary 2014; 17: $333-$ 341.

13. Bex M, Abs R, T'Sjoen G, et al. AcroBel the Belgian registry on acromegaly: a survey of the 'real-life' outcome in 418 acromegalic subjects. Eur J Endocrinol. 2007;157:399-409.

14. Anagnostis P, Efstathiadou ZA, Polyzos SA, et al. Acromegaly: presentation, morbidity and treatment outcomes at a single centre. Int J Clin Pract. 2011; 65:896-902.

15. Mercieca C, Gruppetta M, Vassallo J. Epidemiology, treatment trends and outcomes of acromegaly. Eur J Intern Med. 2012; 23:e206-7.

16. Vallette S, Ezzat S, Chik C, et al. Emerging trends in the diagnosis and treatment of acromegaly in Canada. Clin Endocrinol (Oxf). 2013; 79:79-85.

17. Hoskuldsdottir GT, Fjalldal SB, Sigurjonsdottir HA. The incidence and prevalence of acromegaly, a nationwide study from 1955 through 2013. Pituitary. 2015; 18:803-7.

18. Dal J, Feldt-Rasmussen U, Andersen M, et al. Acromegaly incidence, prevalence, complications and long-term prognosis: a nationwide cohort study. Eur J Endocrinol. 2016; 175:181-90.

19. Portocarrero-Ortiz LA, Vergara-Lopez A, Vidrio-Velazquez M, et al. The Mexican Acromegaly Registry: Clinical and Biochemical Characteristics at Diagnosis and Therapeutic Outcomes. J Clin Endocrinol Metab. 2016; 101:3997-4004.

20. Carmichael JD, Broder MS, Cherepanov D, et al. Long-term treatment outcomes of acromegaly patients presenting biochemically-uncontrolled at a tertiary pituitary center. BMC Endocr Disord. $2017 ; 17: 49$.

21. Lesén E, Granfeldt D, Houchard A, et al. Comorbidities, treatment patterns and cost-of-illness of acromegaly in Sweden: a register-linkage population-based study. Eur J Endocrinol. 2017; $176: 203-212$. 
23. Maione $\mathrm{L}$, Brue $\mathrm{T}$, Beckers $\mathrm{A}$, et al. Changes in the management and comorbidities of acromegaly over three decades: the French Acromegaly Registry. Eur J Endocrinol. 2017; 176:64555.

24. Minniti G, Moroni C, Jaffrain-Rea ML, et al. Prevalence of hypertension in acromegalic 401 patients: clinical measurement versus 24-hour ambulatory blood pressure monitoring. Clin 402 Endocrinol (Oxf). 1998; 48:149-152.

25. Costenaro F, Martin A, Horn RF, et al. Role of ambulatory blood pressure monitoring in 404 patients with acromegaly. J Hypertens. 2016; 34:1357-1363.

26. Ohtsuka H, Komiya I, Aizawa $T$, et al. Hypertension in acromegaly: hereditary hypertensive factor produces hypertension by enhancing IGF-I production. Endocr J. 1995; 42:781-787.

27. Vitale G, Pivonello R, Auriemma RS, et al. Hypertension in acromegaly and in the normal population: prevalence and determinants. Clin Endocrinol (Oxf). 2005; 63:470-476.

28. Schutte AE, Volpe M, Tocci G, et al. Revisiting the relationship between blood pressure and insulin-like growth factor-1. Hypertension 2014; 63:1070-1077.

29. Powlson AS, Gurnell M. Cardiovascular disease and sleep disordered breathing in acromegaly.

412 Neuroendocrinology 2016; 103:75-85.

413 30. Sardella C, Cappellani D, Urbani C, et al. Disease activity and lifestyle influence comorbidities 414 and cardiovascular events in patients with acromegaly. Eur J Endocrinol. 2016;175(5): 443-453.

415 31. Melmed S, Casanueva FF, Klibanski A, et al. A consensus on the diagnosis and treatment of 416 acromegaly complications Pituitary. 2013; 16:294-302.

417 32. Terzolo M, Matrella C, Boccuzzi A, et al. Twenty-four hour profile of blood pressure in patients 418 with acromegaly. Correlation with demographic, clinical and hormonal features. J Endocrinol 419 Invest. 1999; 22:48-54.

420 33. Sardella C, Urbani C, Lombardi M, et al. The beneficial effect of acromegaly control on blood 421 pressure values in normotensive patients. Clin. Endocrinol 2014; 81: 573-581.

422 34. Feld S, Hirschgerg R. Growth Hormone, the insulin-like growth factor system, and the kidney. J 
35. Lin CJ, Mendonca BB, Lucon AM, et al. Growth hormone receptor messenger ribonucleic acid in normal and pathologic human adrenocortical tissues-An analysis by quantitative polymerase chain reaction technique. J Clin Endocrinol Metab 1997; 82:2671-2676.

36. Kamenicky P, S. Viengchareun, A. Blanchard, et al. Epithelial sodium channel is a key mediator of growth hormone induced sodium retention in acromegaly. Endocrinology. 2008; 149 : 3294-3305.

37. Kamenicky P, A. Blanchard, M. Frank, S. et al. Body fluid expansion in acromegaly is related to enhanced epithelial sodium channel (ENaC) activity. J. Clin. Endocrinol. Metab. 2011; 96:21272135.

38. Bielohuby M, Roemmler J, Manolopoulou J, et al. Chronic growth hormone excess is associated with increased aldosterone: a study in patients with acromegaly and in growth hormone transgenic mice. Exp Biol Med (Maywood). 2009; 234:1002-1009.

39. Moller J, Jorgensen JO, Marqversen J, et al. Insulin-like growth factor I administration induces fluid and sodium retention in healthy adults: Possible involvement of renin and atrial natriuretic factor. Clin Endocrinol (Oxf) 2000;52:181-186.

40. Kraatz C, Benker G, Weber F, et al. Acromegaly and hypertension: Prevalence and relationship to the renin-angiotensin-aldosterone system. Klin Wochenschr 1990; 68:583-587.

41. Zacharieva S, Andreeva M, Andonova K. Effect of sodium depletion on the renin-angiotensinaldosterone system and renal prostaglandins in acromegalic patients. Exp Clin Endocrinol. 1990; $96: 213-8$.

42. Mulatero P, Veglio F, Maffei $\mathrm{P}$, et al. CYP11B2-344T/C Gene Polymorphism and Blood Pressure in Patients with Acromegaly. J Clin Endocrinol Metab. 2006; 91:5008-12.

43. Erbas T, Cinar N, Dagdelen S, et al. Association between ACE and AGT polymorphism and cardiovascular risk in acromegalic patients. Pituitary. 2017; 20:569-577.

44. McKnight JA, McCance DR, Hadden DR, et al. Basal and saline-stimulated levels of plasma 
atrial natriuretic factor in acromegaly. Clin Endocrinol 1989; 31:431-438.

45. Brands MW, Manhiani MM. Sodium-retaining effect of insulin in diabetes. Am J Physiol Regul Integr Comp Physiol. 2012; 303:R1101-9.

46. Slowinska-Srzednicka J, Zgliczynski S, Soszynski P, et al. High blood pressure and 453 hyperinsulinaemia in acromegaly and in obesity. Clin Exp Hypertens 1989;A11:407-425.

454 47. Ikeda $\mathrm{T}$, Terasawa $\mathrm{H}$, Ishimura $\mathrm{M}$, et al. Correlation between blood pressure and plasma insulin 455 in acromegaly. J Int Med 1993; 234:61-63.

48. Ezzat S, Forster MJ, Berchtold $\mathrm{P}$, et al. Acromeglay. Clinical and biochemical features in 500 patients. Medicine (Baltimore) 1994; 73:233-240.

49. Jaffrain-Rea ML, Moroni C, Baldelli R, et al. Relationship between blood pressure and glucose tolerance in acromegaly. Clin Endocrinol (Oxf) 2001;54:189-195.

50. Bondanelli M, Ambrosio MR, degli Uberti EC. Pathogenesis and prevalence of hypertension in acromegaly. Pituitary. 2001; 4: 239-249.

51. Grassi G, Mark A, Esler M. The sympathetic nervous system alterations in human hypertension. Circ Res. 2015; 116:976-90.

52. Bondanelli M, Ambrosio MR, Franceschetti $P$, et al. Diurnal rhythm of plasma catecholamines in acromegaly. J Clin Endocrinol Metab 1999; 84:2458-67.

53. Sumbul HE, Koc AS. Hypertension is Common in Patients with Newly Diagnosed Acromegaly and is Independently Associated with Renal Resistive Index. High Blood Press Cardiovasc Prev. $2019 ; 26: 69-75$.

54. Kamide $\mathrm{K}$, Hori $\mathrm{MT}$, Zhu $\mathrm{JH}$, et al. Insulin and insulin-like growth factor-I promotes 470 angiotensinogen production and growth in vascular smooth muscle cells. J Hypertens 2000; 471 18:1051-1056.

55. Rizzoni D, Porteri E, Giustina A, et al. Acromegalic patients show the presence of 473 hypertrophic remodeling of subcutaneous small resistance arteries. Hypertension. 2004; 43:561$474 \quad 565$. 
56. Paisley AN, Izzard AS, Gemmell I, et al. Small vessel remodeling and impaired endothelialdependent dilatation in subcutaneous resistance arteries from patients with acromegaly. J Clin Endocrinol Metab. 2009; 94:1111-7.

57. Maison $\mathrm{P}$, Démolis $\mathrm{P}$, Young $\mathrm{J}$, et al. Vascular reactivity in acromegalic patients: preliminary evidence for regional endothelial dysfunction and increased sympathetic vasoconstriction. Clin Endocrinol (Oxf). 2000; 53:445-51.

58. Ronconi V, Giacchetti G, Mariniello B, et al. Reduced nitric oxide levels in acromegaly: cardiovascular implications. Blood Press. 2005; 14:227-32.

59. Baykan M, Erem C, Gedikli O, et al. Impairment in flow-mediated vasodilatation of the brachial artery in acromegaly. Med Princ Pract. 2009;18:228-32.

60. Yaron M, Izkhakov E, Sack $J$, et al. Arterial properties in acromegaly: relation to disease activity and associated cardiovascular risk factors. Pituitary. 2016; 19:322-31.

61. Anagnostis P, Efstathiadou ZA, Gougoura S, et al. Oxidative stress and reduced antioxidative status, along with endothelial dysfunction in acromegaly. Horm Metab Res. 2013; 45:314-8.

62. Chen $\mathrm{Z}, \mathrm{Yu} \mathrm{Y}, \mathrm{He} \mathrm{M}$, et al. HIGHER GROWTH HORMONE LEVELS ARE ASSOCIATED WITH ERECTILE DYSFUNCTION IN MALE PATIENTS WITH ACROMEGALY. Endocr Pract. 2019 Mar 13.

63. Cersosimo E, DeFronzo RA. Insulin resistance and endothelial dysfunction: the road map to cardiovascular diseases. Diabetes Metab Res Rev. 2006; 22:423-36.

64. Pietrobelli DJ, Akopian M, Olivieri AO, et al. Altered circadian blood pressure profile in patients with active acromegaly. Relationship with left ventricular mass and hormonal values. J Hum Hypertens 2001; 15:601-605.

65. Attal P, Chanson P. Endocrine aspects of obstructive sleep apnea. J Clin Endocrinol Metab. $2010 ; 95: 483-495$.

66. Davì MV, Giustina A. Sleep apnea in acromegaly: a review on prevalence, pathogenetic aspects and treatment. Expert Rev Endocrinol Metab. 2012; 7:55-62. 
501 67. Lavie $\mathrm{P}$, Herer $\mathrm{P}$, Hoffstein V. Obstructive sleep apnoea syndrome as a risk factor for hypertension: Population study. BMJ 2000;320:479-482.

503 68. Bradley TD, Floras JS: Obstructive sleep apnoea and its cardiovascular consequences. Lancet $5042009 ; 373: 82-93$.

505 69. Thomas JDJ, Dattani A, Zemrak F, et al. Renin-Angiotensin System Blockade Improves 506 Cardiac Indices in Acromegaly Patients. Exp Clin Endocrinol Diabetes. 2017; 125:365-367.

507 70. Colao A, Terzolo M, Bondanelli M, et al. GH and IGF-I excess control contributes to blood 508 pressure control: results of an observational, retrospective, multicentre study in 105 hypertensive 509 acromegalic patients on hypertensive treatment. Clin Endocrinol (Oxf). 2008; 69:613-20.

510 71. González B, Vargas G, de Los Monteros ALE, et al. Persistence of Diabetes and Hypertension 511 After Multimodal Treatment of Acromegaly. J Clin Endocrinol Metab. 2018; 103:2369-2375.

512 72. Katznelson L, Laws ER Jr, Melmed S, et al; Endocrine Society. Acromegaly: an endocrine 513 society clinical practice guideline. J Clin Endocrinol Metab. 2014; 99:3933-51.

514 73. Yonenaga M, Fujio S, Habu M, et al. Postoperative Changes in Metabolic Parameters of 515 Patients with Surgically Controlled Acromegaly: Assessment of New Stringent Cure 516 Criteria.Neurol Med Chir (Tokyo). 2018; 58:147-155.

517 74. Jaffrain-Rea ML, Minniti G, Moroni C, et al. Impact of successful transsphenoidal surgery on 518 cardiovascular risk factors in acromegaly Eur J Endocrinol. 2003; 148:193-201.

519 75. Minniti G, Moroni C, Jaffrain-Rea ML, et al. Marked improvement in cardiovascular function 520 after successful transsphenoidal surgery in acromegalic patients Clin Endocrinol (Oxf). 2001; $521 \quad 55: 307-13$.

522 76. Reyes-Vidal C, Fernandez JC, Bruce JN, et al. Prospective study of surgical treatment of 523 acromegaly: effects on ghrelin, weight, adiposity, and markers of CV risk. J Clin Endocrinol Metab. $524 \quad 2014 ; 99: 4124-32$.

525 77. Colao A, Pivonello R, Galderisi M, et al. Impact of Treating Acromegaly First with Surgery or 526 Somatostatin Analogs on Cardiomyopathy J Clin Endocrinol Metab. 2008; 93:2639-46. 
78. Serri O, Beauregard C, Hardy J. Long-Term Biochemical Status and Disease-Related Morbidity in 53 Postoperative Patients with Acromegaly. J Clin Endocrinol Metab. 2004; 89:658-61.

79. Carmichael JD, Bonert VS, Nuño M, et al. Acromegaly Clinical Trial Methodology Impact on Reported Biochemical Efficacy Rates of Somatostatin Receptor Ligand Treatments: A MetaAnalysis. J. Clin. Endocrinol. Metab. 2014; 99: 1825-33.

80. Gadelha $M R$, Bronstein $M D$, Brue $T$ et al. Pasireotide versus continued treatment with octreotide or lanreotide in patients with inadequately controlled acromegaly (PAOLA): a randomised, phase 3 trial. Lancet Diabetes Endocrinol. 2014; 2: 875-84.

81. Ronchi CL, Varca V, Beck-Peccoz P, et al. Comparison between six-year therapy with longacting somatostatin analogs and successful surgery in acromegaly: effects on cardiovascular risk factors. J Clin Endocrinol Metab. 2006; 91:121-8.

82. Colao A, Ferone D, Marzullo $\mathrm{P}$, et al. Long-term effects of depot long-acting somatostatin analog octreotide on hormone levels and tumor mass in acromegaly. J Clin Endocrinol Metab. $2001 ; 86: 2779-86$

83. Maison P, Tropeano AI, Macquin-Mavier I, et al. Impact of somatostatin analogs on the heart in acromegaly: a metaanalysis. J Clin Endocrinol Metab. 2007; 92:1743-7.

84. Colao A, Auriemma RS, Galdiero M, et al. Effects of initial therapy for five years with 544 somatostatin analogs for acromegaly on growth hormone and insulin-like growth factor-I levels, 545 tumor shrinkage, and cardiovascular disease: a prospective study. J Clin Endocrinol Metab. 2009; $54694: 3746-3756$.

547 85. Trainer P, Drake W, Katznelson L et al. Treatment of acromegaly with the growth hormone548 receptor antagonist pegvisomant. N. Engl. J. Med. 2000; 342:1171-1177.

549 86. van der Lely AJ, Hutson RK, Trainer PJ et al. Long-term treatment of acromegaly with 550 pegvisomant, a growth hormone receptor antagonist. Lancet. 2001; 358:1754-59.

551 87. Grottoli S, Maffei P, Bogazzi F et al, ACROSTUDY: the Italian experience. Endocrine. 2015; 552 48: 334-41. 
553 88. Ragonese M, Grottoli S, Maffei $\mathrm{P}$ et al. How to improve effectiveness of pegvisomant treatment 554 in acromegalic patients. J. Endocrinol. Invest. 2017; 41:575-581.

555 89. Puglisi S, Spagnolo F, Ragonese M, et al. First report on persistent remission of acromegaly 556 after withdrawal of long-term pegvisomant monotherapy. Growth Horm IGF Res. 2019; 45:17-19.

557 90. Colao A, Pivonello R, Auriemma RS, et al. Efficacy of 12-month treatment with the GH 558 receptor antagonist pegvisomant in patients with acromegaly resistant to long-term, high-dose 559 somatostatin analog treatment: effect on IGF-I levels, tumor mass, hypertension and glucose 560 tolerance Eur J Endocrinol. 2006; 154:467-77.

561 91. Pivonello R, Galderisi M, Auriemma RS, et al. Treatment with Growth Hormone Receptor 562 Antagonist in Acromegaly: Effect on Cardiac Structure and Performance. J Clin Endocrinol Metab. $5632007 ; 92: 476-82$.

564 92. De Martino MC, Auriemma RS, Brevetti G, et al. The treatment with growth hormone receptor 565 antagonist in acromegaly: effect on vascular structure and function in patients resistant to 566 somatostatin analogues. J Endocrinol Invest. 2010; 33:663-70.

567 93. Auriemma RS, Grasso LF, Galdiero M, et al. Effects of long-term combined treatment with 568 somatostatin analogues and pegvisomant on cardiac structure and performance in acromegaly. 569 Endocrine. 2017; 55:872-884.

570 94. Berg C, Petersenn S, Lahner H, et al. Cardiovascular risk factors in patients with uncontrolled 571 and long-term acromegaly: comparison with matched data from the general population and the 572 effect of disease control. J Clin Endocrinol Metab. 2010; 95:3648-56.

573 95. Briet C, Ilie MD, Kuhn E, et al. Changes in metabolic parameters and cardiovascular risk 574 factors after therapeutic control of acromegaly vary with the treatment modality. Data from the 575 Bicêtre cohort, and review of the literature. Endocrine. 2019; 63:348-360. 
579 Table 1 - Frequency of hypertension (HTN) in acromegaly in studies published over the last 15 years 580 [national or local registries of acromegalic patients].

\begin{tabular}{|c|c|c|c|c|c|c|c|}
\hline Country & $\begin{array}{c}\text { No of } \\
\text { patients* }\end{array}$ & $\begin{array}{c}\text { No of HTN } \\
\text { patients }\end{array}$ & $\begin{array}{c}\text { \% of HTN } \\
\text { patients }^{\#}\end{array}$ & $\begin{array}{c}\text { Mean } \\
\text { age }\end{array}$ & $\begin{array}{l}\text { Study } \\
\text { period }\end{array}$ & $\begin{array}{c}\text { Year of } \\
\text { publication }\end{array}$ & References \\
\hline Spain & 1036 & 405 & 39.1 & 45.0 & $1997-2003$ & 2004 & [3] \\
\hline New Zealand & 126 & 69 & 54.7 & 42.0 & $1964-2000$ & 2004 & [4] \\
\hline Belgium & 409 & 161 & 39.4 & 44.0 & $2000-2004$ & 2007 & {$[13]$} \\
\hline Greece & 84 & - & 46.0 & 47.0 & $1980-2009$ & 2011 & [14] \\
\hline Italy & 1512 & - & 33.0 & 45.0 & $1980-2002$ & 2012 & [6] \\
\hline Malta & 47 & 22 & 46.8 & 43.4 & $1979-2008$ & 2012 & [15] \\
\hline Canada & 537 & 198 & 36.9 & 45.0 & $1980-2010$ & 2013 & {$[16]$} \\
\hline Iceland & 52 & 25 & 48.1 & 44.5 & $1955-2013$ & 2015 & [17] \\
\hline Denmark & 405 & 44 & 11.0 & 48.7 & $1991-2010$ & 2016 & {$[18]$} \\
\hline Mexico & 2057 & - & 27.0 & 41.0 & $2009-\ldots$ & 2016 & [19] \\
\hline USA & 120 & 57 & 47.5 & 55.4 & $1985-2013$ & 2017 & {$[20]$} \\
\hline Sweden & 358 & 142 & 39.7 & 50.0 & $2005-2013$ & 2017 & [21] \\
\hline Germany & 479 & 186 & 45.5 & 45.7 & - - - - 2016 & 2017 & [22] \\
\hline France & 947 & - & 33.0 & 46.0 & $1999-2012$ & 2017 & [23] \\
\hline Weighted mea & & & 33.6 & & & & \\
\hline Range & & & $11.0-54.7$ & & & & \\
\hline
\end{tabular}

$582 \quad{ }^{*}$ if specified, data at diagnosis.

583

584

585

586 
588 Table 2 - Effects of different treatments of acromegaly on hypertension.

\begin{tabular}{|llc|}
\hline TREATMENT & EFFECT ON HTN & REFERENCES \\
& Amelioration of HTN with & [73-78] \\
& conflicting data on a more & \\
Somatostatin analogues & prominent effect on SBP vs. DBP & [81-84] \\
& Possible amelioration of HTN & \\
Pegvisomant & with long-term control of & {$[\mathbf{9 0 - 9 5 ]}$} \\
& acromegaly & \\
Cabergoline & Amelioration of HTN with long- & \\
Radiotherapy & term control of acromegaly & - \\
\hline
\end{tabular}

589 Abbreviations are as follows: HTN, hypertension; SBP, systolic blood pressure; DBP, diastolic

590 blood pressure; NA, not available

591

592

593 FIGURE LEGEND

594

595 Fig 1. Pathogenesis of hypertension in acromegaly. 